\title{
A routine intervention in a highly unusual vessel
}

\author{
A. Gasecka (iD - M. Voskuil · E. E. C. de Waal · M. I. F. J. Oerlemans · F. Ramjankhan · L. W. van Laake · \\ A. O. Kraaijeveld
}

Accepted: 16 August 2021 / Published online: 15 September 2021

(C) The Author(s) 2021

A 31-year-old woman with a HeartWare ${ }^{\mathrm{TM}}$ (Medtronic, Minneapolis, MN, USA) left ventricular assist device (LVAD), which had been implanted for ischaemic cardiomyopathy, presented with progressive dyspnoea. Bilateral pneumonia was suspected. Despite antibiotic treatment, the patient's condition deteriorated: she became more dyspnoeic and developed cardiogenic shock with a low LVAD flow. Computed tomography angiography showed an intraluminal focal outflow graft stenosis. In a multidisciplinary team discussion, the patient was scheduled for an emergency percutaneous intervention via a femoral approach to avoid surgery, based on previous reports [1-3]. Angiography confirmed the stenosis, with an invasive peak-peak gradient of $80 \mathrm{mmHg}$ (Fig. 1a). This was treated with an Advanta V12 balloon-expandable covered stent $(10 \mathrm{~mm} \times 38 \mathrm{~mm})$ and post-dilated with an Advance balloon $(10 \mathrm{~mm} \times 20 \mathrm{~mm})$, resulting in a residual gradient of $10 \mathrm{~mm} \mathrm{Hg}$ and an immediate increase in LVAD flow (Fig. 1b). The patient recovered uneventfully after this procedure.

The incidence of outflow graft stenosis ranges from 0.01 to 0.03 per patient-year [4, 5]. Personalised anticoagulation protocols and surgical implantation techniques are currently being studied to prevent LVAD outflow graft obstruction due to stenosis, thrombosis or torsion.

\footnotetext{
A. Gasecka · M. Voskuil • M. I. F. J. Oerlemans .

L. W. van Laake · A. O. Kraaijeveld $(\bowtie)$

Department of Cardiology, University Medical Centre Utrecht, Utrecht, The Netherlands

a.o.kraaijeveld-3@umcutrecht.nl

\section{E. E. C. de Waal}

Department of Anaesthesiology, University Medical Centre Utrecht, Utrecht, The Netherlands

\section{F. Ramjankhan}

Department of Cardiothoracic Surgery, University Medical Centre Utrecht, Utrecht, The Netherlands
}

Conflict of interest A. Gasecka, M. Voskuil, E.E.C. de Waal, M.I.F.J. Oerlemans, F. Ramjankhan, L.W. van Laake and A.O. Kraaijeveld declare that they have no competing interests.

Open Access This article is licensed under a Creative Commons Attribution 4.0 International License, which permits use, sharing, adaptation, distribution and reproduction in any medium or format, as long as you give appropriate credit to the original author(s) and the source, provide a link to the Creative Commons licence, and indicate if changes were made. The images or other third party material in this article are included in the article's Creative Commons licence, unless indicated otherwise in a credit line to the material. If material is not included in the article's Creative Commons licence and your intended use is not permitted by statutory regulation or exceeds the permitted use, you will need to obtain permission directly from the copyright holder. To view a copy of this licence, visit http://creativecommons.org/licenses/by/4.0/.

\section{References}

1. Wert L, Kaufmann F, Solowjowa N, et al. Diagnosis and treatment strategies of outflow graft obstruction in the fully magnetically levitated continuous-flow centrifugal left ventricular assist device: a multicenter case series. ASAIOJ.2021;67:e52-4.

2. Gertz ZM, Trankle CR, Grizzard JD, et al. An interventional approach to left ventricular assist device outflow graft obstruction. Catheter Cardiovasc Interv. 2021; https://doi. org/10.1002/ccd.29556.

3. Nathan S, Ghotra AS, Rajagopal K, et al. Left ventricular assist device outflow graft obstruction: a case series. ASAIO J. 2020;66:657-62.

4. Burke MA, Alexy T, Kamioka N, et al. Outflow graft obstruction causing recurrent heart failure after left ventricular assist device implantation. J Heart Lung Transplant. 2020;39:S98.

5. Scandroglio AM, Kaufmann F, Pieri M, et al. Diagnosis and treatment algorithm for blood flow obstructions in patients withleft ventricular assist device. JAm Coll Cardiol. 2016;67:2758-68. 
Fig. 1 a Angiography confirming outflow graft stenosis (left panel, red arrow). Advanta V12 balloon-expandable covered stent $(10 \mathrm{~mm} \times 38 \mathrm{~mm})$ in outflow tract (right panel, red arrow). b Invasive blood pressure monitoring demonstrating an $80-\mathrm{mm} \mathrm{Hg}$ gradient over the stenosis before the procedure (upper panel, red arrows) and a residual 10$\mathrm{mmHg}$ gradient after the procedure (lower panel, red arrows)

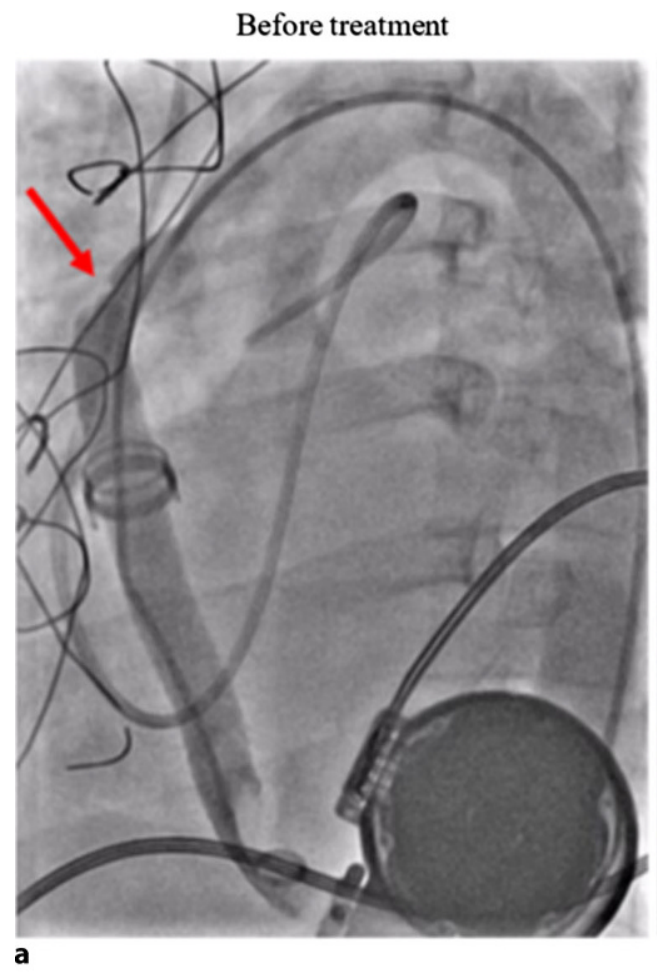

\section{After treatment}
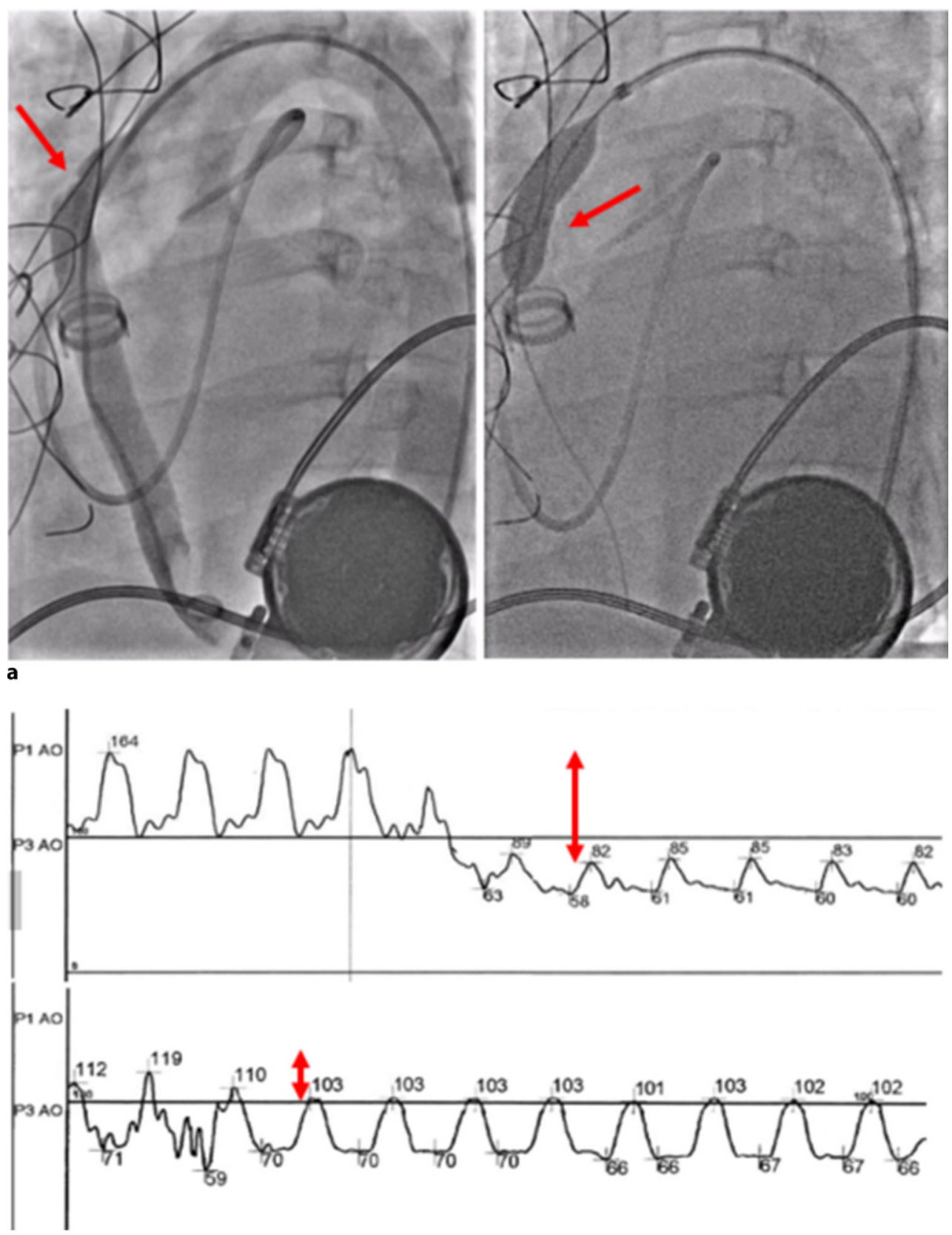